surprising find, made by Prof. Cockerell during the summer of $\mathrm{I} 897$, is a specimen of this species, taken in the Mesilla Valley, on Bigelovia wrightii, August 5. It is the first specimen of the genus ever taken in New Mexico, to my knowledge.

TACHINIDAE s. str.

II. Jurinia lateralis Mcq. Two os (Ckll.), Las Cruces, May 3 and June 9. The former is an undersized specimen, with the abdomen less red on sides.

I2. Gonia sequex Will. Two specimens (Ckll.), Las Cruces. One April 9, on flowers of Prunus domesticus (plum); the other, May 5 .

\title{
A NEW ANT-NEST COCCID.
}

BY GEO. B. KING, LAWRENCE, MASS., AND J. D. TINSLEY, MESILlA PARK, N. MEX.

The species described below was collected by Mr. King. The notes on the microscopical characters were prepared by Mr. King, but have been extended and rewritten from $\mathrm{Mr}$. King's mounts by Prof. Tinsley, who is also responsible for the comparison with allied species. The drawings are by $\mathrm{Mr}$. Tinsley. The notes on the living insect, and habits, etc., are by Mr. King.

Dactylopius claviger, $\mathrm{n} . \mathrm{sp} .-$ Adult $q$. Length 2.5-3.5 mm. Width about $2 \mathrm{~mm}$. Shape, ovoidal, quite plump. Color, dark reddish-brown, covered with white mealy secretion. Segmentation of body distinct, under hand lens. No lateral or caudal appendages. Boiled in caustic potash it colors the liquid a light violet red. Legs and antennae pale yellowish-brown. Antennae 8-jointed ; 8 longest, longer than $6+7$, and with several whorls of hairs, the hairs being numerous at the distal end ; I next longest, its diameter equalling or slightly exceeding its length, a whorl of hairs around its distal end; 2 next, its diameter about $\frac{3}{4}$ of its length, two whorls of hairs, one about midway and the other near distal end; 5 next, with two whorls of hairs, one at each end ; 7 next, with a whorl of hairs about its middle, 3 next ( 3 and 7 are often subequal), its diameter being about $\frac{2}{3}$ of that of 2 , a whorl of hairs about its middle; 4 and 6 about subequal and with a whorl of hairs about the middle. The joint between 4 and 5 is often, almost usually, quite indistinct, and this might be considered a prominent characteristic. Antennal formula 812573 (46). See figure of antenna. Legs, -

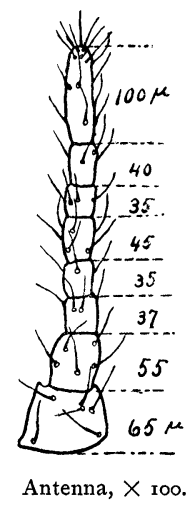

Femur stout being a little over twice as long as wide, quite hairy; tibia, width about $\frac{1}{2}$ the width of the femur, length about equal 
to that of femur, bristly; tarsus a little less than $\frac{1}{2}$ the length of tibia, bristly, tarsal digitules very long, slender, and knobbed; claw medium size and slightly curved, digitules of claw slightly longer than claw, and

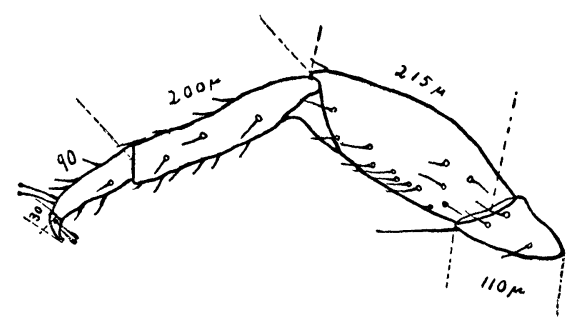

Second leg, $\times$ ıoo.

rather stout. See figure. Anal ring and lobes normal. Ovisac, about $5 \mathrm{~mm}$. long, a fluffy mass of cottony secretion in which the female often entirely buries herself. Eggs pale yellowish brown.

Male unknown.

Habitat, Andover, Mass., Oct. 20, 1896 , in the nest of Lasius claviger Rog. Coll. Geo. B. King; collected again by Mr. King at Methuen, Mass., Oct. 3, 1897, in nests of Lasius americanus Em., "completely concealed in a round ball of cottony down, attached to roots of grass entering the ants' nest, under a stone" (King).

A striking characteristic of this species is that the antennae and femora bear numerous long, slender hairs and that the body also bears numerous long, slender hairs. The relative lengths of the segments of the antennae are much more constant than is usual in ants' nest coccids.

\section{THE LARVAE OF TWO SATURNIANS.}

BY HARRISON G. DYAR, WASHINGTON, D. C.

Hemileuca neumoegeni $\mathrm{Hy}$. Edw. - Almost indistinguishable from the eastern $H$. maia except that the head is black. Upper row of spines (i) with short shaft on joints $5^{-12}$, an unpaired dorsal spine on joints 12 and 13 ; none on the anal plate; four rows of spines on joints 2 to 6 and $\mathrm{II}$, three on the other segments. Secondary hairs abundant, fine, white. Black, head shining; body thickly covered with small yellow dots, approximate, subconfluent, centered by the secondary hairs. An indicated subdorsal, lateral and broader stigmatal yellow bands, showing as dots in the incisures which are mostly otherwise free from the yellow dots. Spines black, the basal ones on each shaft yellowish. Leg plate black; venter a little reddish.

The yellow dots are less confluent than in H. maia, being especially sparse in the in. cisures, and the stigmatal band is reduced and obsolete centrally on the segments.
(I blown example, Los Angeles Co., Cal. bred by Koebele. Coll. U. S. Nat. Mus.)

Agapema galbina: Clemens. - Egg. E1liptical, flattened above and below, a little concave; white, shagreened, covered all over with a brown gum, which causes the eggs to adhere to the twig and is applied irregularly, forming darker brown spots and streaks. Size, $2.6 \times 1.9 \times 1.6 \mathrm{~mm}$. Hatch by a hole in one end; laid in an irregular mass on a twig. (H. K. Morrison, Ariz., May 5th, 1883 ; Coll. U. S. N. M.)

Stage $I$. Head rounded, black with white setae; width I mm. Body black, without secondary hairs, but with four rows on thorax, three elsewhere of 'low, scarcely produced warts, each bearing several pale hairs mixed with some dark ones. Hairs stiff, somewhat curved. Warts all paired, no single dorsal one, the pair on the anal plate small and rudimentary. Tubercles of equal size, those on joints 4, 5, and I2 scarcely perceptibly larger; anal plate shining; skin faintly transversely wrinkled; no markings; claspers of abdominal feet pale, but leg-plates dark, shining. Length $5 \mathrm{~mm}$. 

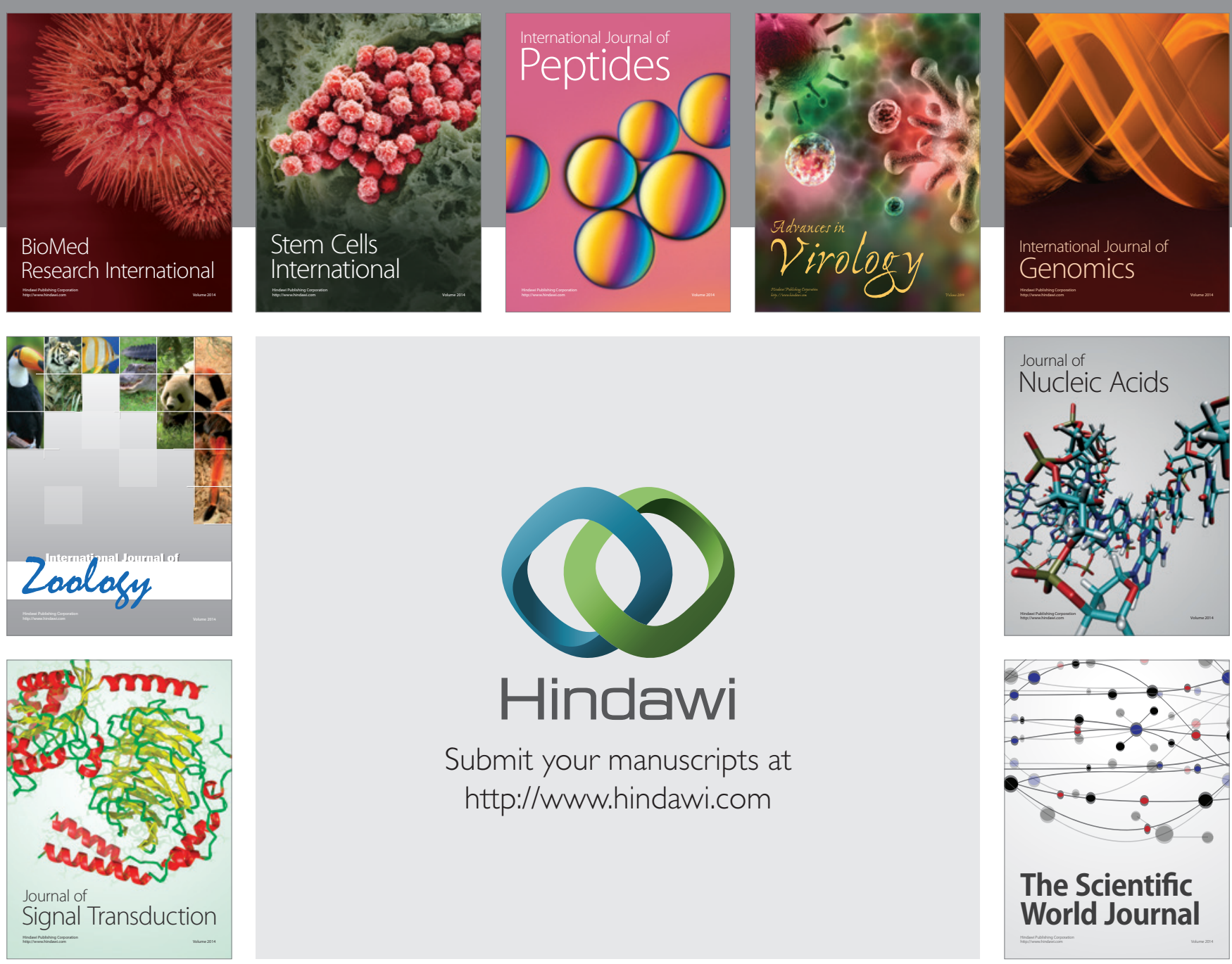

Submit your manuscripts at

http://www.hindawi.com
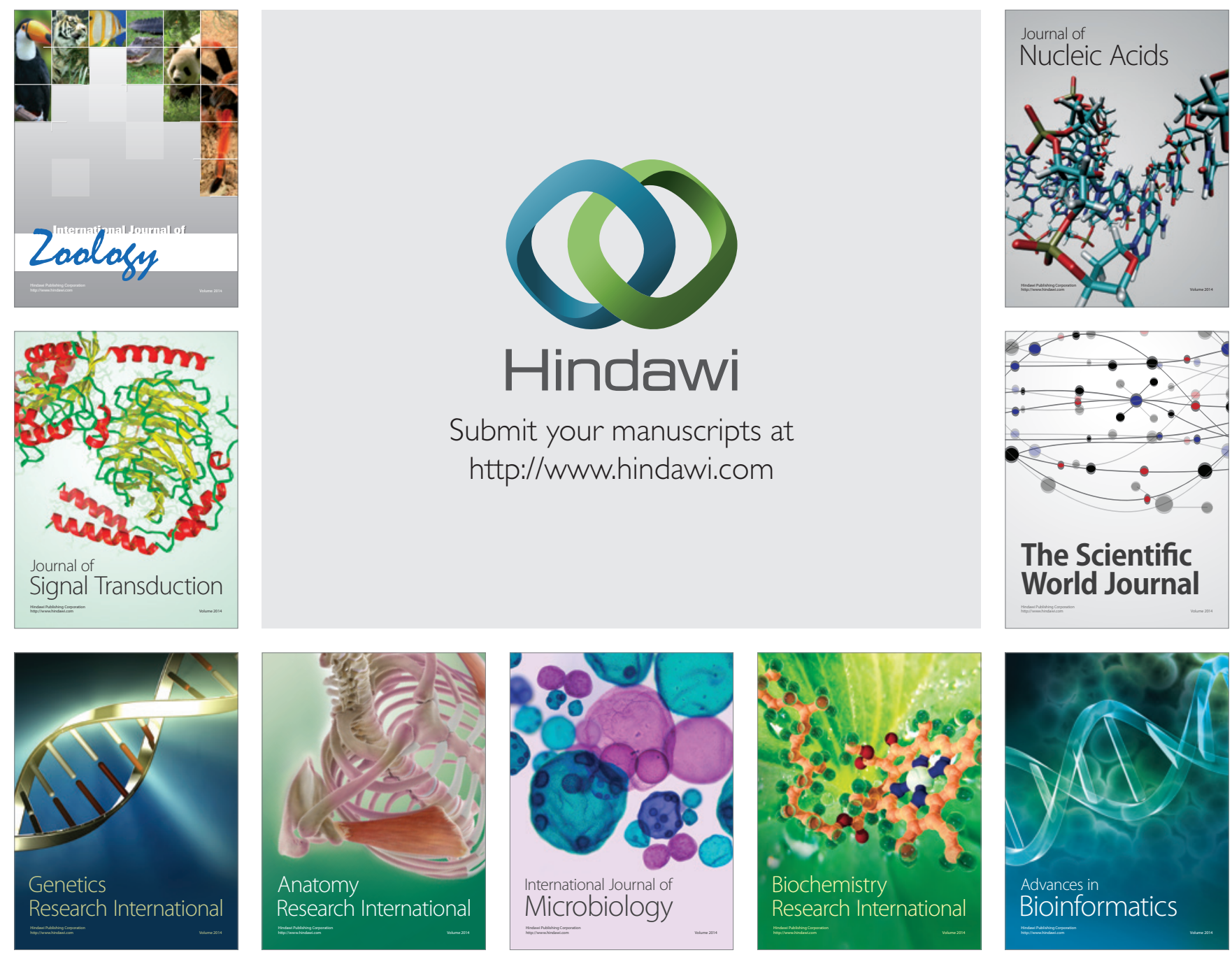

The Scientific World Journal
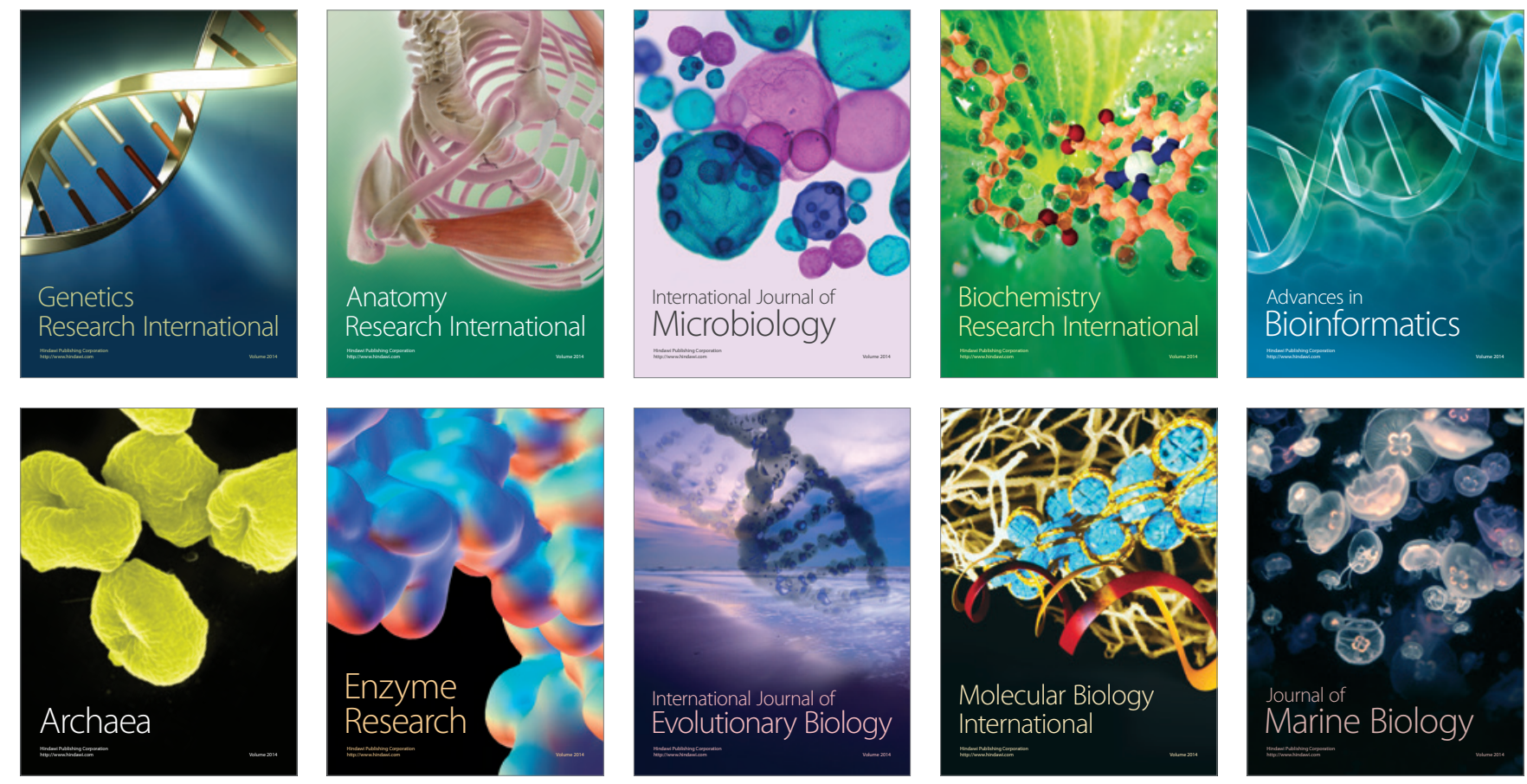